\title{
TYPE 2 DIABETES MELLITUS - IL-8 AND IL-10 PROFILE IN PATIENTS WITH INTRAABDOMINAL POSTOPERATIVE ABSCESSES
}

D0I: $10.36740 /$ Wek202002102

\author{
Valeriy V. Boyko, Artem S. Riga \\ KHARKIV NATIONAL MEDICAL UNIVERSITY, KHARKIV, UKRAINE
}

\begin{abstract}
The aim: To assess of pro-inflammatory IL-8 and anti-inflammatory IL-10 serum concentration in patients with T2DM with intraabdominal postoperative abscesses in perioperative period.

Materials and methods: The 48 participants, aged 40 - 75 years, among them 24 males and 24 females. All patients were divided into groups: group 1-12 patients with T2DM and intra-abdominal postoperative abscesses, group 2 - 12 patients without T2DM but with intra-abdominal postoperative abscesses and 24 healthy individuals. The level of IL-8 and IL-10 serum was determined on the day before surgery, on the 2-3rd and 5-7th day after surgery in patients with type 2 diabetes and intra-abdominal postoperative abscesses. Results and conclusions: The trajectories of the level of interleukins in patients with type 2 Diabetes mellitus were different from the trajectories of their level in patients without diabetes, which indicates a special immune response to nosocomial infection and surgical trauma. The mechanism of changes in serum levels of IL-8 and IL-10 in patients with type 2 Diabetes mellitus and postoperative intra-abdominal abscesses should be further studied in future studies on the specific causative agent of nosocomial infection and the cytokine response to it.
\end{abstract}

KEY WORDS: type 2 Diabetes mellitus, postoperative intra-abdominal abscesses, interleukin-8, interleukin-10

\section{INTRODUCTION}

Type 2 diabetes mellitus (T2DM) is a global epidemic costly condition $[1,2]$. Individuals with T2DM sustain reduction in quality of life, and high prevalence of morbidity and mortality [3].

The pathophysiology of T2DM has enough been studied [4]. The infections are more in patients with T2DM with the course of them is more complicated. One of the possible causes of this increased prevalence of infections is defects in immunity. It depends on hyperglycemia, decreased immune cellular responses [5].

Many clinical conditions generally require expensive and time-consuming investigations for their diagnosis. The very important problem in surgery is a diagnosis and management of postoperative abscesses, especially in patients with T2DM. There is therefore a general need for exploring non-invasive markers in clinical medicine. Interleukin-8 (IL-8) and interleukin-10 (IL-10) is currently being applied in various subspecialties of medicine either for the purpose of rapid diagnosis or as a predictor of prognosis [6].

\section{THE AIM}

To assess of pro-inflammatory IL-8 and anti-inflammatory IL-10 serum concentration in patients with T2DM with intraabdominal postoperative abscesses in perioperative period. Hypothesis: There is a difference in serum IL- 8 and IL-10 between diabetics and non-diabetic patients with intra-abdominal postoperative abscesses in perioperative period.

\section{MATERIALS AND METHODS}

A case-control study is designed to compare of clinical course of perioperative period and cytokines (IL- 8 and IL-10) at the day before surgical intervention, at the $2^{\text {nd }}-3^{\text {rd }}$ day and $5^{\text {th }}-7^{\text {th }}$ day after surgical intervention in patients with T2DM and intra-abdominal postoperative abscesses due to intra-abdominal infections.

The 48 participants were recruiting from the Hospital of State Enterprise "'Institute of General and Emergency Surgery named after V.T.Zaytsev" NAMS of Ukraine" in 2016-2018 aged 40 - 75 years, among them 24 males and 24 females. All patients were divided into groups: group $1-12$ patients with T2DM and intra-abdominal postoperative abscesses, group $2-12$ patients without T2DM but with intra-abdominal postoperative abscesses and 24 healthy individuals.

Inclusion criteria. 1. Having intra-abdominal postoperative abscesses and T2DM. 2. Willingness to participate. 3. Age: 40-75 years old.

Exclusion criteria. Patients who do not presented intra-abdominal postoperative abscesses with T2DM and those who do not agreed to participate of this study.

Blood samples. For immunological analysis, it was obtained of $5 \mathrm{ml}$ blood from 24 healthy volunteers and each 
patient (group 1 and 2) by vacuum sterile disposable tubes (Vacutainer) at the day before surgical intervention, on $2^{\text {nd }}-3^{\text {rd }}$ day and on $5^{\text {th }}-7^{\text {th }}$ day after surgical intervention. Serum was centrifuged at $800 \mathrm{~g}$ for $10 \mathrm{~min}$ at $4^{\circ} \mathrm{C}$ and has stored at $-20^{\circ} \mathrm{C}$. Extracellular IL- 8 and IL-10 in the serum was assessed with VectorBESTUkraine test system cytokines kit, according to manufacturer's instructions in immune enzyme analyzer "LabLine-90" (Austria).

Ethical Considerations. This study was approved by the Ethics Committee of the Kharkiv National Medical University (Report No 6 from 05.10.2016). Informed consent was obtained for every patient.

Statistical analyses. Normality of data distribution is evaluated using Kolmogrov-Smirnov test. Comparison of data between two groups is done by Mann-Whitney $\mathrm{U}$ (not normal distribution). Comparison of percentages was performed using the Fisher criterion. Statistical descriptive analysis was performed with the MedCalc Software (Acacialaan 22 B-8400 Ostend, Belgium), for all statistical methods, $\mathrm{p}<0.05$ was considered statistically significance.

\section{RESULTS}

There were previous surgical interventions due to intra-abdominal infections among patients of $1^{\text {st }}$ and $2^{\text {nd }}$ group. All patients took antibacterial therapy according hospital local protocol. Among patients with T2DM all were medication-treated, 10 have had diabetic complications: polyneuropathy (4/12), retinopathy (4/10), urine albumin excretion $(2 / 12)$. The average glycated hemoglobin (A1C) level was $9.6 \%$.

The common comorbidities, surgical approaches, and demographic date of patients are present in Table 1.

The manifestation of postoperative abscesses, complains, characteristics, surgical approaches and demographic data of patients with and without T2DM have not significant difference as well as characteristics of origin of intra-abdominal infections and localization of postoperative abscesses. Difference was in variation of days of hospitalization in patients both group. The median, minimal and maximal value of serum IL- 8 in 24 healthy individuals were $72,08(16,68 ; 96,36) \mathrm{pg} / \mathrm{ml}$, serum IL-10 $-4,87(2,35 ; 8,94) \mathrm{pg} / \mathrm{ml}$.

We obtained statistically significant differences of serum concentrations of IL- 8 and IL- 10 in $1^{\text {st }}$ and $2^{\text {nd }}$ group's patients at the day before surgery, at $2^{\text {nd }}-3^{\text {rd }}$ day and $5^{\text {th }}-7^{\text {th }}$ day after surgery compared with the values of healthy individuals. So we obtained statistically significant differences of serum concentrations of IL-8 and IL-10 comparing $1^{\text {st }}$ and $2^{\text {nd }}$ group's patients (Table 2).

The distribution of cytokines levels by day in the perioperative period shows that both IL-8 and IL-10 are significantly lower in patients with T2DM: pro-inflammatory IL-8 is reduced by $5^{\text {th }}-7^{\text {th }}$ days, and anti-inflammatory IL- 10 is reduced by $2^{\text {nd }}-3^{\text {rd }}$ days of the postoperative period in serum and saved so by $5^{\text {th }}-7^{\text {th }}$ days. The level of serum IL- 8 was increasing in patients with postoperative intra-abdominal abscesses and without T2DM by the $5^{\text {th }}-7^{\text {th }}$ day of the postoperative period. The level of anti-inflammatory IL-10 was significant higher in patients without T2DM. It suggest about mature immune reaction to nosocomial infection and surgical trauma.

\section{DISCUSSION}

According to numerous publications, T2DM is a risk factor for the development of intra-abdominal infections $[7,8]$. Chronic hyperglycemia contributes to increase the risk of gastrointestinal infectious processes [5].

The most studies show decreased functions of diabetic polymorph nuclear cells and diabetic monocytes/macrophages compared to cells of healthy persons [9]. But the data on the level of cytokines are contradictory. So, study of Cimini F.A. et al, demonstrates that serum IL-8 is increased in diabetic patients [10]. Similarly contradictory information regarding the concentration of serum IL-10: mononuclear cells and monocytes of persons with T2DM secrete less cytokines in response to stimulation by lipopolysaccharides [5]. However, other studies reported that the increased glycation could inhibit the production of IL-10 by myeloid cells, impairing cell immunity [11]. Some investigators claim that the differences in the risk factors for infection between diabetic and non-diabetic patients result either from non-controlled studies or biased studies However, most researchers conclude that there is clinical evidence pointing to the higher prevalence of infectious diseases among individuals with T2DM [7, 12].

Of course, the immune response of the cytokine profile varies in patients with bacterial infection of the intra-abdominal cavity. But no final result has been achieved with respect to the determination of the levels of interleukins. Some study shows increasing serum IL-8 and IL-10, as well as their decreasing in the perioperative period in other studies $[13,14]$.

Our study showed that both pro-inflammatory and anti-inflammatory interleukins IL- 8 and IL-10 in formation of postoperative intra-abdominal abscesses have low values compared with the values of healthy individuals, and the lowest values in patients with T2DM. The combination of T2DM and postoperative intra-abdominal abscesses is accompanied by a complex relationship between the immune response of the macroorganism and nosocomial flora.

A low level of serum pro-and anti-inflammatory response to infection in T2DM explains the longer hospitalization of patients with postoperative intra-abdominal abscesses.

Assessing the risk of formatting of postoperative intra-abdominal abscesses in patients with T2DM is important for infection's agents' control, and antimicrobial therapy, and control of diabetes. In a matched cohort study using a Canadian electronic medical record-based surveillance system, the odds of any infection were higher among 1779 patients with diabetes (22 percent on insulin) compared with 11,066 matched controls, after controlling for potential confounders (adjusted odds ratio 1.21, 95\% CI 1.07-1.37) [15].

In another retrospective cohort study using a large primary care database in England, the incidence rate ratio (IRR) for any infec- 
Table 1. Clinical characteristics, surgical approaches and demographic data of patients

\begin{tabular}{|c|c|c|c|}
\hline Data & Group 1, n=12 & Group 2, n=12 & $\mathbf{p}$ \\
\hline Age, years $(\text { Median, }(\min ; \max ))^{*}$ & $\begin{array}{c}63 \\
(53 ; 70)\end{array}$ & $\begin{array}{c}61 \\
(50 ; 69)\end{array}$ & 0.5641 \\
\hline Men, $\mathrm{n}(\%)$ & $5(42)$ & $7(58)$ & 0.4415 \\
\hline Systemic arterial hypertension, $\mathrm{n}(\%)$ & $8(67)$ & $6(50)$ & 0.4071 \\
\hline Obesity (increase than $20 \%$ of an individual's ideal body weight), n (\%) & $4(33)$ & $2(17)$ & 0.3752 \\
\hline Body temperature $>38.0^{\circ} \mathrm{C}, \mathrm{n}(\%)$ & $5(42)$ & $8(67)$ & 0.2318 \\
\hline Critical state at hospital admission, n (\%) & $3(25)$ & $5(42)$ & 0.3842 \\
\hline Chronic cholicystitis/pancreatitis, n (\%) & $5(42)$ & $3(25)$ & 0.3842 \\
\hline Duration in hospital, days (Median, $(\min ; \max ))^{*}$ & $13(8 ; 98)$ & $17(7 ; 34)$ & 0.0489 \\
\hline Minimally invasive surgical intervention (abscess punction), n (\%) & $10(83)$ & $12(100)$ & 0.1847 \\
\hline Hepatic abscess, n (\%) & $7(58)$ & $5(42)$ & 0.4415 \\
\hline Subhepatic abscess, n (\%) & $1(8)$ & $2(17)$ & 0.5120 \\
\hline Subphrenic abscess, n (\%) & $1(8)$ & $4(33)$ & 0.1435 \\
\hline Mixed abscess localization, $\mathrm{n}(\%)$ & $3(25)$ & $1(8)$ & 0.2740 \\
\hline
\end{tabular}

*Mann-Whitney test

Table 2. Distribution of IL-8 and II-10 serum level in patients in perioperative period

\begin{tabular}{|c|c|c|c|}
\hline Perioperative period & $\begin{array}{c}\text { Group } 1 \\
n=12\end{array}$ & $\begin{array}{c}\text { Group } 2 \\
n=12\end{array}$ & $\mathbf{p}$ \\
\hline & \multicolumn{3}{|c|}{ IL-8, pg/ml, median, (min; max) } \\
\hline Day before surgical intervention & $\begin{array}{c}27,11 \\
(18,09 ; 48,42)\end{array}$ & $\begin{array}{c}38,44 \\
(20,11 ; 59,55)\end{array}$ & 0.1955 \\
\hline $2^{\text {nd }}-3^{\text {rd }}$ day after surgical intervention & $\begin{array}{c}23,99 \\
(17,31 ; 40,7)\end{array}$ & $\begin{array}{c}38,39 \\
(16,99 ; 64,4)\end{array}$ & 0.0683 \\
\hline \multirow[t]{2}{*}{$5^{\text {th }}-7^{\text {th }}$ day after surgical intervention } & $\begin{array}{c}20,08 \\
(12,13 ; 30,81) \\
\end{array}$ & $\begin{array}{c}43 \\
(19,78 ; 56,5)\end{array}$ & 0.0358 \\
\hline & \multicolumn{3}{|c|}{ IL-10, pg/ml, median, (min; max) } \\
\hline Day before surgical intervention & $\begin{array}{c}12,08 \\
(7,62 ; 18,16) \\
\end{array}$ & $\begin{array}{c}17,86 \\
(9,06 ; 28,1) \\
\end{array}$ & 0.0683 \\
\hline $2^{\text {nd }}-3^{\text {rd }}$ day after surgical intervention & $\begin{array}{c}7,26 \\
(4,87 ; 14,93) \\
\end{array}$ & $\begin{array}{c}12,89 \\
(6,06 ; 22,91)\end{array}$ & 0.0449 \\
\hline $5^{\text {th }}-7^{\text {th }}$ day after surgical intervention & $\begin{array}{c}7,5 \\
(4,39 ; 15,17)\end{array}$ & $\begin{array}{c}12,68 \\
(4,03 ; 21,03)\end{array}$ & 0.0349 \\
\hline
\end{tabular}

tion was higher among 5863 patients with type 1 diabetes mellitus (IRR 1.66, 95\% CI 1.59-1.74) and 96,930 with T2DM (1.47, 95\% CI 1.46-1.49) compared with age, sex, and practice-matched controls ( $n=11,696$ for type 1 and $n=191,822$ for type 2) [16].

Our data decrease serum IL-8 level in perioperative period both patients with or without T2DM are corresponding data of Zhengwen Xiao et al. [13] and João Fernando Gonçalves Ferreira et al. [17] which proved that the greatest concentration of IL- 8 is contained in the inflammatory focus compared with serum.

Our data corresponding data about cell-mediated immunity are all depressed in diabetics with hyperglycemia that were published in 1997 and $2000[18,19]$. Our result supports that correct choice of antibiotic therapy early during infection is important to prevent not only bacterial over growth, but also uncontrolled inflammation and uncontrolled
T2DM. Accordingly, Barnett et al. also observed that nosocomial-acquired infections are more severe, requiring longer hospitalization and showing higher death rates in risk-group patients. [20].

\section{CONCLUSIONS}

The mechanism of value serum IL-8 and IL-10 in patients with T2DM and postoperative intra-abdominal abscesses should be explored with future studies targeting a specific causative agent of nosocomial infection and cytokine response.

\section{REFERENCES}

1. Kahn SE, Cooper ME, Del Prato S. Pathophysiology and treatment of type 2 diabetes: perspectives on the past, present, and future. Lancet. 2014; 383(9922):1068-83. 
2. Lopez JM, Bailey RA, Rupnow MF, Annunziata K. Characterization of type 2 diabetes mellitus burden by age and ethnic groups based on a nationwide survey. Clin Ther. 2014; 36(4):494-506.

3. Sakineh Shab-Bidar, Tirang R Neyestani, Abolghassem Djazayery. Efficacy of vitamin D3-fortified-yogurt drink on anthropometric, metabolic, inflammatory and oxidative stress biomarkers according to vitamin $D$ receptor gene polymorphisms in type 2 diabetic patients: a study protocol for a randomized controlled clinical trial. Shab-Bidar et al. BMC Endocrine Disorders 2011, 11:12 http://www.biomedcentral. com/1472-6823/11/12 (22 June 2011)

4. Defronzo RA. Banting Lecture. From the triumvirate to the ominous octet: a new paradigm for the treatment of type 2 diabetes mellitus. Diabetes. 2009; 58 (4):773-95.

5. Juliana Casqueiro, Janine Casqueiro, Cresio Alves. Infections in patients with diabetes mellitus: A review of pathogenesis. Indian J Endocrinol Metab. 2012 Mar; 16(Suppl1):S27-S36. doi: 10.4103/2230-8210.94253

6. Aamir Shahzad, Martin Knapp, Irene Lang, Gottfried Köhler. Interleukin 8 (IL-8) - a universal biomarker? Int Arch Med. 2010; 3: 11. Published online 2010 Jun 15. doi: 10.1186/1755-7682-3-11

7. John E. Mazuski,Jeffrey M. Tessier, Addison K. May, Robert G. Sawyer, Evan P. Nadler, Matthew R. Rosengart, Phillip K. Chang, Patrick J. O'Neill, Kevin P. Mollen, Jared M. Huston, Jose J. Diaz, Jr, Jose M. Prince The Surgical Infection Society Revised Guidelines on the Management of Intra-Abdominal Infection. Surgical Infections. Volume 18, Number 1, 2017. doi: 10.1089/sur.2016.261

8. Updated Guideline on Diagnosis and Treatment of Intra-abdominal Infections. World J Emerg Surg. 2017; 12: 22. Published online 2017 May 4. doi: 10.1186/s13017-017-0132-7

9. Suzanne E. Geerlings Andy I.M. Hoepelman. Immune dysfunction in patients with diabetes mellitus (DM). FEMS Immunology \& Medical Microbiology, Volume 26, Issue 3-4, 1 December 1999, Pages 259-265, https://doi.org/10.1111/j.1574-695X.1999.tb01397.x

10. Cimini FA, Barchetta I, Porzia A, Mainiero F, Costantino C, Bertoccini L, Ceccarelli V, Morini S, Baroni MG, Lenzi A, Cavallo MG. Circulating IL-8 levels are increased in patients with type 2 diabetes and associated with worse inflammatory and cardiometabolic profile. Acta Diabetol. 2017 0ct;54(10):961-967. doi: 10.1007/s00592-017-1039-1. Epub 2017 Aug 23.

11. Price $\mathrm{CL}$, Al Hassi HO, English NR, Blakemore Al, Stagg AJ, Knight SC. Methylglyoxal modulates immune responses: relevance to diabetes. J Cell Mol Med. 2010;14:1806-15.

12. Muller LM, Gorter KJ, Hak E, Goudzwaard WL, Schellevis FG, Hoepelman $\mathrm{Al}$, et al. Increased risk of common infections in patients with type 1 and type 2 diabetes mellitus. Clin Infect Dis. 2005;41:281-8.

13. Zhengwen Xiao, Crystal Wilson, Helen Lee Robertson, Derek J. Roberts, Chad G. Ball, Craig N. Jenne, Andrew W. Kirkpatrick. Inflammatory mediators in intra-abdominal sepsis or injury - a scoping review. Crit Care. 2015; 19: 373. doi: 10.1186/s13054-015-1093-4

14. Stein K, Lysson M, Schumak B, Vilz T, Specht S, Heesemann J, Roers A, Kalff JC, Wehner S. Leukocyte-Derived Interleukin-10 Aggravates Postoperative lleus. Front Immunol. 2018 Nov 13; 9:2599. doi: 10.3389/ fimmu.2018.02599.
15. Abu-Ashour W, Twells LK, Valcour JE, Gamble JM. Diabetes and the occurrence of infection in primary care: a matched cohort study. BMC Infect Dis 2018; 18:67.

16. Carey IM, Critchley JA, DeWilde S, et al. Risk of Infection in Type 1 and Type 2 Diabetes Compared With the General Population: A Matched Cohort Study. Diabetes Care 2018; 41:513.

17. João Fernando Gonçalves Ferreira, João Baptista Rezende-Neto, Rogério Augusto Pinto-Silva, Jaqueline Gontijo de Souza, Luiz de Macêdo Farias, Maria Auxiliadora Roque de Carvalho, Helton Santiago, José Carlos Serufo, Simone Gonçalves dos Santos. Microbiota Evaluation and Extracellular Cytokine Profile in Patients Affected with Intraabdominal Infection. British Journal of Medicine \& Medical Research, 2016;15(4):114. DOI: $10.9734 / B J M M R / 2016 / 25281$

18. Delamaire $M$, Maugendre $D$, Moreno $M$, et al. Impaired leucocyte functions in diabetic patients. Diabet Med 1997; 14:29.

19. Llorente L, De La Fuente H, Richaud-Patin Y, et al. Innate immune response mechanisms in non-insulin dependent diabetes mellitus patients assessed by flow cytoenzymology. Immunol Lett 2000; 74:239.

20. Barnett AG, Page K, Campbell M, Martin E, Rashleigh-Rolls R, Halton $\mathrm{K}$, Paterson DL, Hall L, Jimmieson N, White K, Grave N. The increased risks of death and extra lengths of hospital and ICU stay from hospitalacquired bloodstream infections: A case-control study. BMJ Open. 2013;3:e003587, 1-6

\section{ORCID and contributionship:}

Valeriy V. Boyko - 0000-0003-0702-637X A,E,F

Artem S. Riga - 0000-0003-2130-5260 ${ }^{B, C, D, F}$

\section{Conflicts of interest:}

Authors declare no conflict of interest.

\section{CORRESPONDING AUTHOR Artem S. Riga \\ Department of Surgery No 1 , Kharkiv National Medical University \\ Nauki ave, 4, 61022, Kharkiv, Ukraine \\ tel: +380577077380 \\ e-mail: yaartyom888@gmail.com}

Received: 11.05 .2019

Accepted: 20.12.2019

\footnotetext{
A - Work concept and design, B - Data collection and analysis, C - Responsibility for statistical analysis, D-Writing the article, $\mathbf{E}$ - Critical review, $\mathbf{F}$ - Final approval of the article
} 